\section{Effects of color differences}

\section{in a letter matching task*}

\author{
ARNOLD D. WELL and JOANNE GREEN
}

University of Massachusetts, Amherst, Mass. 01002

Ss were required to judge whether pairs of letters were identical with respect to name (Experiment 1) or form (Experiment 2). The results replicated the findings of Posner \& Mitchell (1967) that physically identical letters could be matched more quickly than those only sharing the same name. When members of a letter pair differed in color, Ss showed a small but reliable tendency to respond more slowly when making "same" judgments, even when the letters only shared the same name. "Different" judgments were unaffected by color differences. To account for the effects of color variation, it seems necessary to consider both distraction and response competition factors.

Posner and a number of co-workers (e.g., Posner \& Mitchell, 1967; Posner, 1969) have provided evidence for the isolability of operations performed on the visual representations of letters and those performed on letter names. Consider a situation in which $S$ is presented with two letters and is instructed to judge whether or not they have the same name. If the letters are physically identical (e.g., A and A), it is logically possible to make such a judgment purely on the basis of visual information. On the other hand, given letters like $A$ and $a$, which are not physically identical, the match is necessarily based on a learned correspondence between the visual information and a letter name. Posner found that "same" judgments could be made 70-100 msec faster to physically identical letters than to letters having only the same name. He also found that "different" responses could be made to two letters differing in form (e.g., A and B) $70-100 \mathrm{msec}$ faster when the criterion for sameness was physical identity than when it was name identity. Moreover, the times to make physical matches seem to be systematically affected by visual factors, whereas name matches are affected primarily by factors related to the letter name, such as the number of letter names held in short-term store (Posner, 1969). On the basis of such evidence, Posner has argued that visual and name information is matched at different levels in the system.

If this is indeed the case, one might expect that variation on an irrelevant dimension such as color may have an effect on the matching of letters identical in form, in which case, presumably, judgments are based on visual factors but not on the matching of letters having only a learned name in common. The purpose of the

*This research was supported in part by a grant from the Research Council of the University of Massachusetts/Amherst. present experiments was to examine the effects of varying color as an irrelevant dimension in a letter-matching task.

\section{EXPERIMENT 1}

In Experiment 1, Ss were required to judge whether or not two simultaneously presented letters had the same name.

\section{Subjects} Massachusetts undergraduates who received course credit for their participation. Ss served for two 1-h sessions on consecutive days.

Apparatus

Stimulus slides were rear-projected by two Kodak RA-950 random axis slide projectors operated by a PDP-8I computer. Each projector displayed one of the two letters used in a given trial. The computer was also used to present warning signals and to record responses.

\section{Stimuli}

Stimulus displays consisted of pairs of letters. Letters could be either in upper- or lowercase and were chosen from among $\mathrm{A}, \mathrm{B}, \mathrm{C}$, and $\mathrm{E}$. The letters were presented side by side and subtended a horizontal visual angle of 2.8 deg. Each block of 64 trials contained 16 letter pairs in which both letters were identical with respect to form (FI), 16 pairs in which the letters had the same name but differed in case (NI), and 32 pairs in which the letters differed in name (diff). Each pair appeared as two colored letters on a dark background. On $75 \%$ of the trials, both letters appeared in the same color (basic color), which was red for five Ss and green for the other five. On $25 \%$ of the trials, one of the letters appeared in a different color (secondary color), which was green if the basic color was red and red if the basic color was green. When it occurred, the secondary color was assigned randomly to the left or right letter. Displays were presented in a random order subject to the constraint
The Ss were 10 University of that within each trial block, $25 \%$ of the trials of each type (FI, NI, or diff) contained one letter in the secondary color.

\section{Procedure}

The Ss were run individually in a dimly lit sound-damped room. Ss were seated about $8 \mathrm{ft}$ from the projection screen and indicated their judgments by using their middle fingers to depress buttons located on a console located in front of them. Instructions emphasized both speed and accuracy and stated that a "same" response was to be made if the members of a pair had the same name; otherwise, a "different" response was to be made.

Each day began with 32 practice trials, following which data were collected from three blocks of 64 trials. A trial began with the onset of a 0.5 -sec burst of white noise, which served as a warning signal. One second following the onset of the warning signal, the two letters appeared and remained visible until a response was made. Because of the relatively long times required by the projectors to select slides, the intertrial interval was set at 7 sec.

\section{Results and Discussion}

The major findings are presented in Table 1.

An analysis of variance examining the effects of basic color (C), day (D), irrelevancy condition (I), and type of letter pair (T) was performed. The analysis revealed significant main effects for $T[F(2,16)=63.86$, $\mathrm{p}<.001], \mathrm{I}[\mathrm{F}(1,8)=6.73, \mathrm{p}<.05]$, and $D[F(1,8)=19.63, p<.01]$. No interactions were significant. For both FI $[t(9)=2.90, p<.02]$ and NI $[t(9)$ $=2.31, \mathrm{p}<.05]$ pairs, the presence of color variation resulted in longer response latencies. Although neither the $\mathrm{D}$ by I nor the $\mathrm{D}$ by I by $\mathrm{T}$ interactions were significant, the effects of color variation did show a tendency to diminish over days. For NI pairs, effects declined from $29 \mathrm{msec}$ on Day 1 to $27 \mathrm{msec}$ on Day 2, whereas for FI pairs, effects declined from $32 \mathrm{msec}$ on Day 1 to $8 \mathrm{msec}$ on Day 2. The overall error rate was $2.5 \%$ and tended to be slightly higher for those cases in which color variation was present. The differences in effects of color variation for FI and NI pairs was not significant.

Table 1

Mean Reaction Time Data from Experiment 1

\begin{tabular}{crrr}
\hline $\begin{array}{c}\text { Presence of } \\
\text { Secondary } \\
\text { Color }\end{array}$ & \multicolumn{3}{c}{ Types of Letter Pairs } \\
\cline { 2 - 4 } & FI & NI & Diff \\
\hline No & 504 & 578 & 610 \\
Yes & 524 & 606 & 610 \\
Difference & 20 & 28 & 0 \\
\hline
\end{tabular}


Table 2

Mean Reaction Time Data from Experiment 2

\begin{tabular}{crrr}
\hline $\begin{array}{c}\text { Presence of } \\
\text { Secondary } \\
\text { Color }\end{array}$ & \multicolumn{3}{c}{ Types of Letter Pairs } \\
\cline { 2 - 4 } & FI & NI* & Diff \\
\hline No & 484 & 486 & 476 \\
Yes & 514 & 486 & 483 \\
Difference & 30 & 0 & 7 \\
\hline
\end{tabular}

*In Experiment 2, NI pairs required "different" responses.

The data replicated earlier findings that FI pairs can be matched more rapidly than NI pairs. They further indicate that color variation had effects for both kinds of letter pairs but say little about how cclor variation had its effects. It is possible, for instance, that in the case of FI matches, color variation caused matches on some trials to be made on the basis of name information rather than on visual information, whereas on other FI trials, color may have been ignored. To assess the effects of color variation in a task in which all judgments were required to be made on the basis of visual information, a second experiment was conducted in which the criterion for sameness was changed from name identity to form identity.

\section{EXPERIMENT 2}

Subjects

Sixteen University of Massachusetts undergraduates served for two sessions on consecutive days.

Apparatus and Stimuli

The apparatus and stimuli were identical to those used in Experiment 1.

Procedure

The procedure was the same as in
Experiment 1, except that $S$ was required to base "same" and "different" responses on visual form rather than on letter name. Since stimuli had the same characteristics as those used in Experiment 1, 75\% of the letter pairs now required "different" responses (NI and diff pairs).

Results and Discussion

The major results are presented in Table 2 .

Although the data were subjected to a number of analyses, the major result is simply that color variation had a significant effect $[\mathrm{t}(15)=4.75$, $\mathrm{p}<.001$ ] on FI matches and no effect on matches requiring "different" responses. Although Ss were faster in all conditions on Day 2 than on Day 1 $[F(1,14)=35.1, p<.001]$, effects of color variation on FI matches remained fairly stable, diminishing from $34 \mathrm{msec}$ on Day 1 to $26 \mathrm{msec}$ on Day 2. Overall error rate was $2.2 \%$ and again tended to be slightly higher for trials in which the secondary color was present.

The data from the two experiments indicate that color variation had effects on performance both when matches were based on visual information and when matches were based on name information. Posner (1969) implies that the name code is relatively independent of its visual context once it has been extracted. It, therefore, seems unlikely that color information could have interfered with the actual matching of the name codes. Since the effects of irrelevant color differences did not apparently differ for "same" responses made to FI and NI pairs in Experiment 1, it may also be the case that color differences did not interfere directly with the matching of encoded visual representations of form. It seems more plausible to consider as an explanation of the data (1) some initial distraction due to color variation which may have disrupted a level of encoding preceding both visual and name matches, or (2) a tendency to respond on the basis of color information which may have competed with the primary response. Neither explanation seems entirely adequate to explain the obtained results. The distraction hypothesis would imply increased latencies in the presence of color variation for both "same" and "different" responses. The competing response hypothesis, on the other hand, might imply that there should be some facilitation of "different" responses when color differences were present. No evidence of such facilitation was observed in the present experiments, although in a subsequent experiment which otherwise replicated the results of Experiment 1 with a somewhat different design, a small (13-msec) but significant facilitation effect for "different" responses was obtained. The present data can be accounted for if one assumes that both distraction and competing response factors play a role in determining the effects of irrelevant color variation. In the case of "same" responses, both factors would tend to increase response latency, whereas in the case of "different" responses, they would tend to cancel one another.

\section{REFERENCES}

POSNER, M. I., \& MITCHELL, R. F Chronometric analysis of classification. Psychological R eview, 1967, 74, 392-409. POSNER, M. I. Abstraction and the process of recognition. In G. Bower (Ed.), Advances in learning and motivation. New Y ork: Academic Press, 1969. 